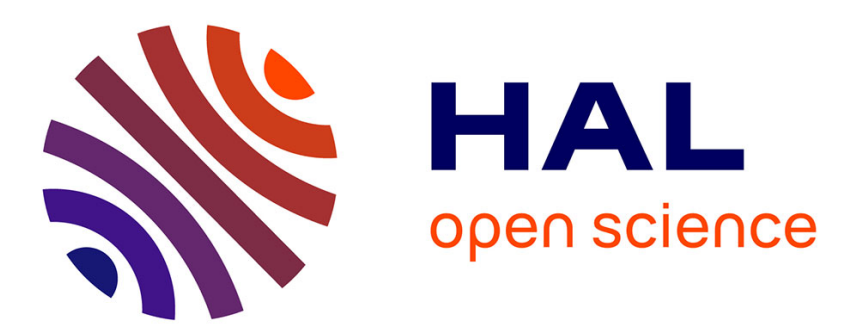

\title{
Stochastic optimization of an Electric Vehicle Fleet Charging with Uncertain Photovoltaic Production
}

Roman Le Goff Latimier, B Multon, Hamid Ben Ahmed, Franck Baraer, Mickael Acquitter

\section{- To cite this version:}

Roman Le Goff Latimier, B Multon, Hamid Ben Ahmed, Franck Baraer, Mickael Acquitter. Stochastic optimization of an Electric Vehicle Fleet Charging with Uncertain Photovoltaic Production. 4th International Conference on Renewable Energy Research and Applications (ICRERA 2015), Nov 2015, Palerme, Italy. pp.721-726, 10.1109/ICRERA.2015.7418505 . hal-01312894

\section{HAL Id: hal-01312894 \\ https://hal.science/hal-01312894}

Submitted on 9 May 2016

HAL is a multi-disciplinary open access archive for the deposit and dissemination of scientific research documents, whether they are published or not. The documents may come from teaching and research institutions in France or abroad, or from public or private research centers.
L'archive ouverte pluridisciplinaire HAL, est destinée au dépôt et à la diffusion de documents scientifiques de niveau recherche, publiés ou non, émanant des établissements d'enseignement et de recherche français ou étrangers, des laboratoires publics ou privés. 


\section{Stochastic optimization of an Electric Vehicle Fleet Charging with Uncertain Photovoltaic Production}

\author{
R. Le Goff Latimier, B. Multon \\ H. Ben Ahmed \\ SATIE lab, ENS Rennes, France \\ roman.legoff-latimier@ens-rennes.fr
}

\author{
F. Baraer \\ Meteo France \\ Rennes, France
}

\author{
M. Acquitter \\ Langa Solar \\ La Meziere, France
}

\begin{abstract}
Simultaneous development of photovoltaic generation and electric vehicles strengthens the solicitations on the electric power system. This paper investigates the possible synergy between these players to jointly improve the production predictability while ensuring a low carbon mobility. It stands for a step towards a quantification of its economic and environmental fallout. First a context is described for a PV-EV collaboration. Then this is gathered into an optimization problem. Grid commitment constraints, battery aging and mobility needs are here considered from the environmental point of view of equivalent primary energy. Finally, a resolution method is presented which achieve an time-efficient optimization of the power flow for each vehicle, based on upstream computed charging policies. It relies on a stochastic modeling of both vehicles availability and forecast error of the PV production. The resolution framework is the stochastic dynamic programming, coupled with on-line minimization so as to avoid the curse of dimensionality. The proposed resolution enables to compute optimal power flow for each vehicle, even among large fleets. The emphasis is here set on a versatile resolution method which could take over many detailed objective functions.
\end{abstract}

Index Terms-Electric vehicles, Photovoltaic systems, Vehicle to Grid, Dynamic programming

\section{INTRODUCTION}

Despite of its environmental performance, large scale photovoltaic $(\mathrm{PV})$ production is bounded by its limited predictability and high variability that enhances solicitations and raises needs for spinning reserves as highlighted by Canova et al. [1]. The introduction of large scale storage unit into the grid is one of the investigated solutions so as to compensate for production variability [2] [3]. The impact of the electrochemical aging mechanism on the bulk storage of electricity relevance has besides been highlighted by Lippert et al [4].

Furthermore, the development of electric vehicles (EV) leads to additional stresses on the grid and increases electricity consumption. Yet, electric mobility can only be a viable alternative to petroleum fuels if the well-to-tank conversion has a light environmental impact. The electricity demand rise should thus be provided by clean plants. Up to now, integrating a significant share of the vehicle fleet come along with forwarding pricing rules so as to make consumption match production. Moreover, EV fleets represent a flexible load which could even become a storage capacity spread over the grid. Indeed, EV fleets could participate to the grid

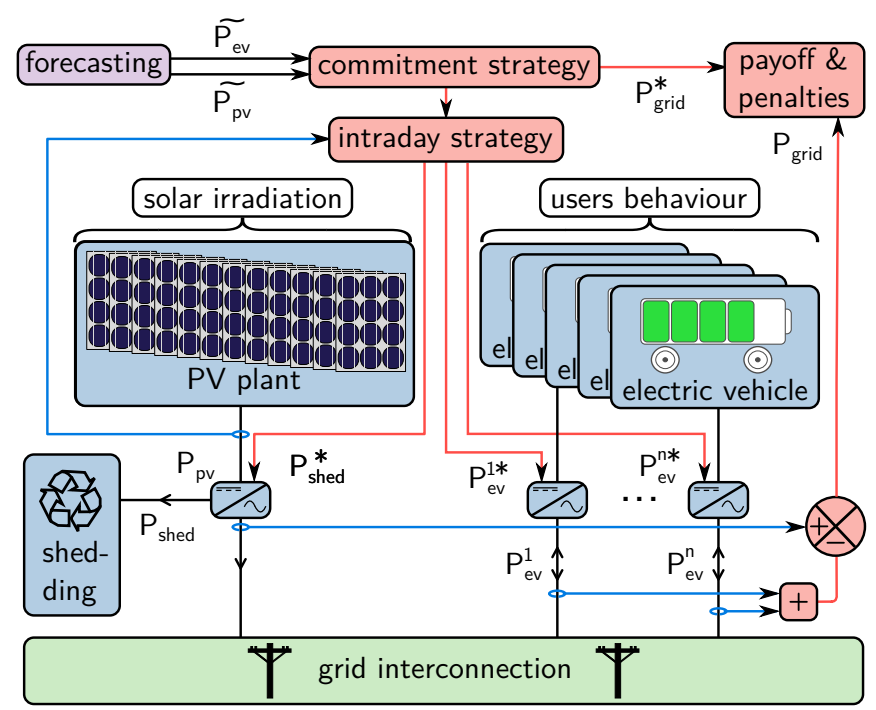

Figure 1. Main players of the collaborative system and associated variables. It would also be possible to consider a single grid connection point.

management [5]. We here consider bidirectional chargers so as to cover situations of temporary vehicle discharging.

An example of such a grid service is a direct association of a PV plant and a EV fleet, managed by a common information system. Guillou et al [6] considered it with the sole aim of maximizing the self consumption of the solar production. Vaya et al. [7] has suggested a remote collaboration between wind farms and EV fleets, which is on-line solved as a multitimestep optimal power flow problem. Indeed, such a collaboration could possibly lead to a reduced production variability while ensuring a sustainable mobility.

The present study first will describe a framework for such a collaborative system (see figure 1), which aims at both meeting a commitment profile for the power injected to the grid while ensuring the vehicle charging. The power management of this system is set as an optimization problem. Despite a resolution by dynamic programming seems doomed with respect to the system large dimension, an efficient resolution is described which combines off line control policies and online minimization. Beyond the objectives that are here picked for description purpose, the proposed resolution method can 
handle numerous concerns, for instance grid constraints or multi-generation units systems, that can not be presented here. It stands for a step towards a quantification of economic and environmental fallout of collaboration in energy systems [9].

\section{DESCRIPTION OF THE COLLABORATIVE SYSTEM}

The framework which is here used is an attempt toward a partnership between EV fleets and renewable sources in order to both foster the grid integration and ensure a sustainable mobility. It relies on a joint management of a fleet charging and a photovoltaic plant as firstly presented in [8]. In the present case study, the goal is to build an operator who could be considered from the grid manager point of view as a single actor, to some extend similar to a virtual power plant (VPP). Indeed, managing an EV fleet into a VPP has been experimented by Binding et al [10].

Main players and associated variables are summarized in figure 1. Production units and EV fleet are supposed to handle together a commitment constraint over the day ahead power profile $P_{g r i d}^{*}$. They suffer some penalties according to the gap between commitment profile and achieved profile. The commitment profile has been computed using imperfect forecasts of PV production $\widetilde{P_{p v}}$ and vehicles charging needs $\widetilde{P_{e v}}$. According to real time situation, the best dispatch between $n_{e v}$ vehicles should then be found for each vehicle power $P_{e v}^{i}, i \in \llbracket 1 ; n_{e v} \rrbracket$ and shedding power $P_{\text {shed }}$, which represents the possibility not to produce the maximum producible power $P_{p v}$. This possibility is achieved through the power point regulation of the PV plant which permits to disoptimize the efficiency of the conversion [11].

The instantaneous power flow into this system is written as follows:

$$
P_{p v}(t)=P_{\text {shed }}(t)+\sum_{i=1}^{n_{e v}} P_{e v}^{i}(t)+P_{\text {grid }}(t)
$$

where $P_{\text {grid }}$ is the net resulting power injected to the grid.

\section{Scope of the collaborative system}

The definition of a collaborative system framework aims at gathering into a single mathematical description many different situations. For instance, cases of a domestic solar roof with personal electric vehicle or of a solar charging station whose production is mainly dedicated to the vehicles correspond to a unique interconnection point with the grid and a commitment profile set to $P_{\text {grid }}^{*}=0$. The collaborative system is then on a single location. Another example is a market agent PV producer who manages a remote EV fleet to reduce his commitment gap penalties. To enlarge the scope to the broader range, the emphasis is both on the versatility of the problem definition and on the resolution methodology.

\section{DEFINITION OF AN OPTIMIZATION PROBLEM}

Considering a discrete time context, managing a collaborative system to maximize its profitability means computing at each time step $\Delta T$ the shedding power $P_{\text {shed }}$ and the charging power of each vehicle $P_{e v}^{i}, i \in \llbracket 1 ; n_{e v} \rrbracket$ with $n_{e v}$ the number of vehicles. This profitability could either be considered from an economy or an environmental point of view, under the same methodology. Several antagonist concerns are at stake and some of them are enumerated below. As indicated supra, the scope is here neither to set up precise modeling for each of these objective [12], or to propose some business model for the collaborative system [13] by a combination of these objective functions. As the emphasis is instead on the resolution methodology, rough even though relevant modeling are firstly chosen for each concern. Then the environmental criterion of the equivalent primary energy is on purpose selected since it may be regarded as a general welfare.

- mobility valuation $C_{m o b}^{i}$ : the vehicle is supposed to ensure his owner mobility while being used for a grid service. The user interest is thus to have his battery charged by the departure time $t_{2}$ he indicated at arrival time $t_{1} . C_{m o b}$ then depends on the state of energy at the departure time $S_{o} E_{e v}^{i}\left(t_{2}\right)$. As a first intention, the primary energy used to refill the battery is considered:

$$
C_{m o b}^{i}\left(S o E_{e v}^{i}\left(t_{2}\right)\right)=E_{e v}^{i \sharp} \cdot\left(\frac{S o E_{e v}^{i}}{\eta_{P V}}+\frac{1-S o E_{e v}^{i}}{\eta_{E U}}\right)
$$

where $E_{e v}^{i \sharp}$ is the capacity of each vehicle. The share of energy which is provided by photovoltaic is balanced by the PV efficiency $\eta_{P V}=E_{\text {life }}^{P V} / E_{e m b}^{p v}$, the ratio of the energy produced over life and the embodied energy. We here adopted $E_{e m b}^{P V}=7 M W h_{\text {prim }} / k W_{\text {peak }}[14]$ and $E_{\text {life }}^{P V}=30 \mathrm{MWh} / \mathrm{k} W_{\text {peak }}$ with a 20 year life and a measured potential of $1500 \mathrm{kWh} / \mathrm{k} W_{\text {peak }} /$ year in this real case study. The energy provided by any other plant through the grid is weighted by mean efficiency of the European energy mix $\eta_{E U}=0.3 \mathrm{kWh} / \mathrm{kWh} h_{\text {prim }}$.

- battery aging $C_{a g e}^{i}$ : providing another service than mobility cannot but bring about additional damage to the battery. The here chosen modeling assigns an elementary damage $d_{i}$ to each solicitation, defined by $d^{i}=\alpha \cdot\left(P_{e v}^{i}\right)^{\beta}$. An elementary damage is similar to spend a share of the battery embodied energy.

$$
C_{a g e}^{i}\left(P_{e v}\right)=\left(d^{i}-d_{0}^{i}\right) \cdot E_{e m b}^{b a t} \cdot E_{e v}^{i \sharp}
$$

where $E_{e m b}^{b a t}=200 k W h_{\text {prim }} / k W h$ [15] is the battery embodied energy and $d_{0}^{i}$ the damage done when no grid service is provided, ie when charging at rated power.

- grid penalties $C_{m i s}$ : the collaboration main added value is to reduce the grid commitment mismatch $\Delta P_{\text {grid }}=$ $P_{\text {grid }}-P_{\text {grid }}^{*}$. For any commitment gap, another plant has to compensate for the missing energy with the European generation efficiency $\eta_{E U}$.

$$
C_{m i s}\left(\Delta P_{\text {grid }}\right)=\frac{\Delta T \cdot \Delta P_{\text {grid }}}{\eta_{E U}}
$$

- shedding power $C_{\text {shed }}$ : Shedding a share of potential $\mathrm{PV}$ production is equivalent to burden its environmental performance $\eta_{P V}$.

$$
C_{\text {shed }}\left(P_{\text {shed }}\right)=\eta_{P V} \cdot \Delta T \cdot P_{\text {shed }}
$$


- Some other concerns could be added such as grid congestion. There are not considered in the following, although they could be handled by the here described methodology.

The minimization of the global cost can thus be set up as the following optimization problem :

$$
\begin{array}{r}
\min _{P_{\text {ev }}, P_{\text {shed }}} \sum_{t}\left\{C_{\text {mis }}\left(\Delta P_{\text {grid }}(t)\right)+C_{\text {shed }}\left(P_{\text {shed }}(t)\right)+\right. \\
\left.\sum_{i=1}^{n_{e v}}\left\{C_{\text {age }}\left(d_{i}(t)\right)+C_{\text {mob }}\left(E_{\text {ev }}^{i}\left(t_{2}^{i}\right)\right)\right\}\right\}
\end{array}
$$

subject to $\forall t, \forall i$,

$$
\begin{aligned}
\text { state of charge constraint: } & S o E_{e v}^{i} \in[0 ; 1] \\
\text { charging power limits: } & P_{e v}^{i} \in\left[P_{e v}^{i b} ; P_{e v}^{i \sharp}\right] \\
\text { shedding limits: } & P_{s h e d} \in\left[0, P_{p v}\right] \\
\text { initial state of energy: } & S o E_{e v}^{i}\left(t_{1}\right)=S o E_{e v}^{i, 0} \\
\text { dynamic equation: } & f_{d y n}\left(S o E_{e v}^{i}, P_{e v}^{i}\right) \\
& S o E_{e v}^{i}(t+\Delta T)=S o E_{e v}^{i}(t)+\frac{\Delta T \cdot P_{e v}^{i}(t)}{E_{e v}^{i \sharp}}
\end{aligned}
$$

The state vector $X$ of this problem is made of the capacity of each vehicle $\left(E_{e v}^{i \sharp}\right)_{i=1: n_{e v}}$, the state of energy of each vehicle $\left(S o E_{e v}^{i}\right)_{i=1: n_{e v}}$ and the forecast error $\Delta P_{p v}(t)$. Control vector $U$ is composed of the charging power vector $P_{e v}=\left(P_{e v}^{1} \ldots P_{e v}^{n_{e v}}\right)$ and the shedding power $P_{\text {shed }}$. The resolution of this optimization problem is challenging because of its stochastic nature, its large scale when handling large fleets, and finally the inertia of the battery storage which brings a temporal coupling. Moreover, this optimization should result in an operational decision, computable at each time step. This particularities call for the preliminary development of strategies which would cover all the possible situations. Real time management could thus be limited to the interpolation of these policies. Stochastic Dynamic Programming [16] [17] enables to draw such strategies, describing for each situation what is the optimal decision in a stochastic context. Vehicles being supposed to daily commute, the horizon of this optimization is midnight, each day being an independent problem. The Bellman equation of problem (6) is therefore:

no cost at the horizon time: $V($ midnight,$X)=0$

$$
\begin{array}{r}
\forall t<\text { midnight, } \forall X:=\left[\left(E_{e v}^{i \sharp}, S O E_{e v}^{i}\right)_{i=1: n_{e v}}, \Delta P_{p v}\right] \\
V(t, X)=\min _{U} C_{\text {shed }}\left(P_{\text {shed }}\right)+C_{m i s}\left(\Delta P_{\text {grid }}\right) \\
+\sum_{i=1}^{n_{e v}}\left\{C_{a g e}\left(d_{i}\right)+\mathbf{1}_{t=t_{2}^{i}} \cdot C_{m o b}\left(S o E_{e v}^{i}\right)\right\} \\
+\mathbb{P}\left(\Delta P_{p v}(t+\Delta T) \mid \Delta P_{p v}(t)\right) \cdot V\left(t+\Delta T, f_{\text {dyn }}(X, U)\right)
\end{array}
$$

$V$ is built all along the algorithm and stores the optimal cost that can be achieved if the system is in a given state $X$ at a time $t$ and follows the optimal strategy $U^{*}$, concurrently computed by $\operatorname{argmin} V(t, X)$. As the forecast error is a random phenomenon $\mathbb{P}\left(\Delta P_{p v}(t+\Delta T) \mid \Delta P_{p v}(t)\right)$, a modeling of its evolution is mandatory to compensate it as well as possible [19]. It is here done by a specially designed cross approach of typical main patterns, associated to a variability and time structure around these main trajectories. Main typical patterns are build using a hierarchical classification and have been identified on a 3 year dataset gathering the production of a $2.64 M W_{\text {peak }} \mathrm{PV}$ plant in Corsica and its forecast by Meteo France, using the AROME model [20].

The main drawback of this optimization method is the curse of dimensionality which is raised by the dimension of the state vector $X$. As each possible situation of $X$ has to be considered, the computational cost increases exponentially with $X$ [21] [22]. The following sections will present a case specific decomposition of (12) into two auxiliary problems, achieving an efficient approximation of the future cost $V$.

\section{OPTIMAL POLICY FOR A STATIONARY ENERGY STORAGE WITHOUT ELECTRIC VEHICLE}

The addition of a stationary energy storage device to a PV unit so as to enhance the grid commitment compliance is here used as a first step towards the association of renewable plants with EV fleets. Optimal storage strategies have been computed by Haessig et al [18] in the case of wind power generation. As the EV fleet is in this section replaced by a stationary storage unit, equation (1) becomes:

$$
P_{p v}(t)=P_{\text {shed }}(t)+P_{\text {sto }}(t)+P_{\text {grid }}(t)
$$

The state vector $X_{\text {sto }}$ of this problem is simpler than $X$ in algorithm (12). It is made of the storage capacity $E_{s t o}^{\sharp}$, the state of energy $S o E_{\text {sto }}$ and the measured forecast error $\Delta P_{p v}$ which is necessary for estimating future hazards probabilities. The control vector $U_{\text {sto }}$ is the shed power $P_{\text {shed }}$ and the storage power $P_{\text {sto. }}$. Keeping in mind that this stationary storage problem is a step toward the fleet management, the optimization horizon is still a day. Considered costs for this problem are shedding $C_{\text {shed }}$ and commitment mismatch $C_{m i s}$.

Stochastic dynamic programming algorithm can then be carried out as follows:

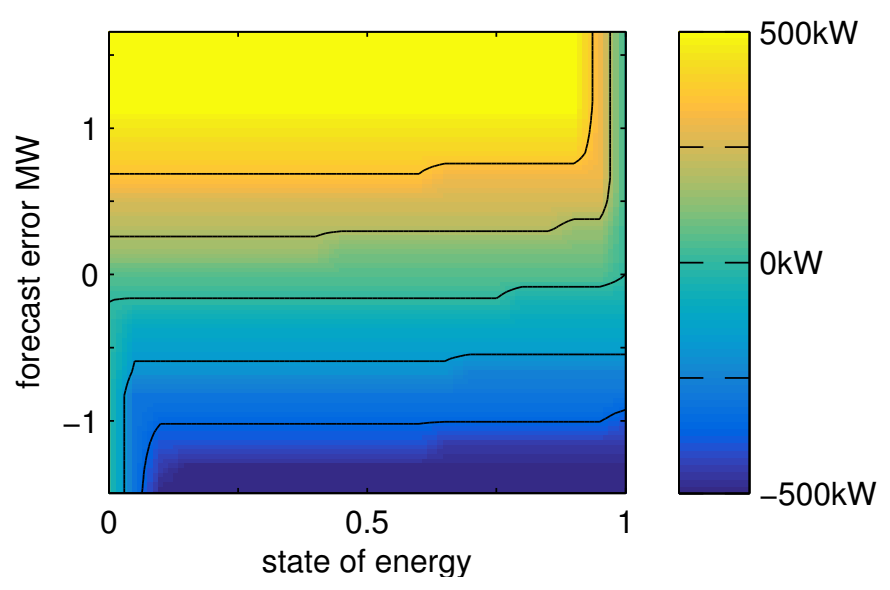

Figure 2. Sectional view of the optimal storage strategy $P_{\text {sto }}$ without EV at $t=2 \mathrm{pm}$ and $E_{\text {sto }}^{\sharp}=5 M W h . P_{P V}^{\text {rated }}=2.64 M W$ 


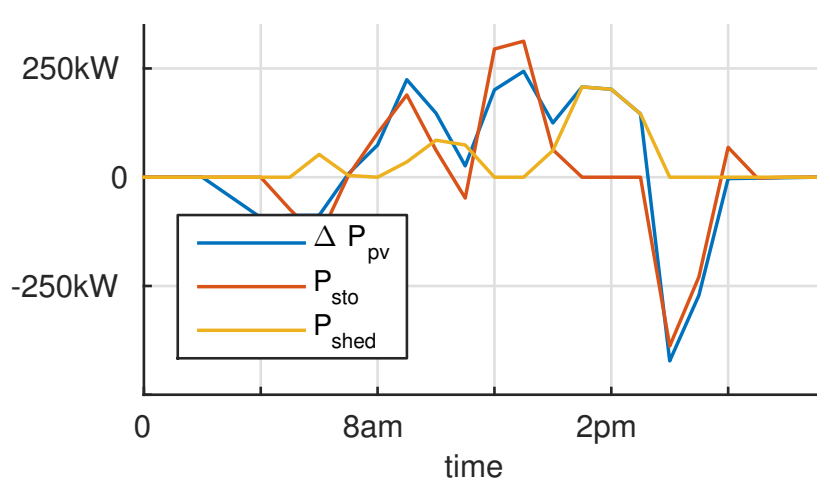

Figure 3. Example of the optimal policy $U_{\text {sto }}^{*}$ applied over a day for a 2.64 $M W$ PV plant and a 1.25 $M W h$ storage. $\Delta T=1 h$

no cost at the horizon time: $V_{\text {sto }}\left(\right.$ midnight, $\left.X_{\text {sto }}\right)=0$

$\forall t<$ midnight, $\forall X_{\text {sto }}:=\left[E_{\text {sto }}^{\sharp}, S o E_{\text {sto }}, \Delta P_{p v}\right]$,

$$
V_{\text {sto }}\left(t, X_{\text {sto }}\right)=\min _{U_{\text {sto }}} C_{\text {shed }}\left(P_{\text {shed }}\right)+C_{\text {mis }}\left(\Delta P_{\text {grid }}\right)
$$

$+\mathbb{P}\left(\Delta P_{p v}(t) \mid \Delta P_{p v}(t-\Delta T)\right) \cdot V_{\text {sto }}\left(t+\Delta T, f_{\text {dyn }}\left(X_{\text {sto }}, U_{\text {sto }}\right)\right)$

A sectional view of the optimal storage power $P_{\text {sto }}^{*}$ contained in $U_{\text {sto }}^{*}$ is represented figure 2 according to the measured forecast error $\Delta P_{p v}(t)$ and the state of energy $S o E_{s t o}$, for a particular time $t=2 \mathrm{pm}$, storage capacity $E_{\text {sto }}^{\sharp}=$ $1.25 M W h$ and main trajectory of the forecast error. In this particular example, as the main trajectory of the forecast error has been supposed to over-estimate the production, most of the considered situations lead to a positive optimal stored power.

Here is defined for further use the following notation for the minimized quantity at each time step :

$$
\Upsilon_{\text {sto }}\left(t, X_{\text {sto }}, U_{\text {sto }}\right):=C_{\text {shed }}\left(P_{\text {shed }}\right)+C_{\text {mis }}\left(\Delta P_{\text {grid }}\right)+
$$

$$
\mathbb{P}\left(\Delta P_{p v}(t+\Delta T) \mid \Delta P_{p v}(t)\right) \cdot V_{\text {sto }}\left(t+\Delta T, f_{\text {dyn }}\left(X_{\text {sto }}, U_{\text {sto }}\right)\right)
$$

Figure 3 represents an application case of this storage and shedding policy for a $2.64 \mathrm{MW} \mathrm{PV}$ plant and a $1.25 \mathrm{MWh}$ storage capacity.

\section{OPTIMAL POLICY FOR VEHICLE CHARGING WITHOUT PV PLANT}

Similarly to the storage strategy computed in the previous section, a charging strategy for a single vehicle will now be defined. The last section will merge them to achieve the joint management of the collaborative system. The EV strategy aims at begin charged by the leaving hour and at minimal cost. The state vector $X_{e v}$ is made of the battery capacity $E_{e v}^{\sharp}$ and the state of energy $S o E_{e v}$. Time is measured as the remaining duration $\tau$ before the user will get his vehicle back. This duration is linked to the departure time $t_{2}$ by:

$$
\tau=t_{2}-t
$$

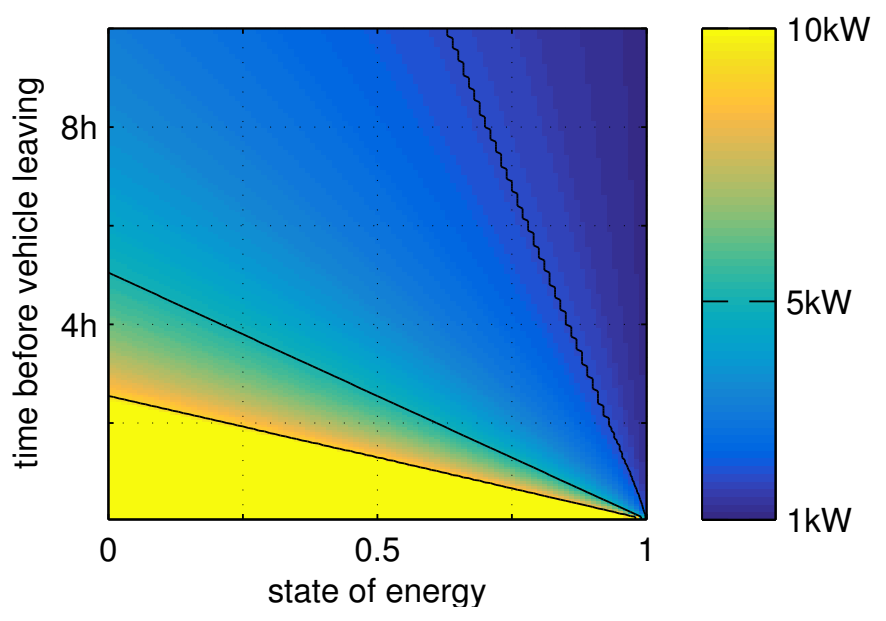

Figure 4. Optimal policy of a vehicle charging power $P_{e v}$, computed by dynamic programming, for a $25 k W h$ capacity.

The control $U_{e v}$ is here the vehicle charging power $P_{e v}$. Battery aging $C_{a g e}$ and user mobility $C_{m o b}$ are taken into account. This problem being deterministic, dynamic programming algorithm is implemented as follows :

final cost at the horizon $V_{e v}\left(\tau=0, X_{e v}\right)=C_{m o b}\left(S o E_{e v}\right)$

$$
\begin{aligned}
& \forall \tau>0, \forall X_{e v}:=\left[E_{e v}^{\sharp}, S o E_{e v}\right], \\
& V_{e v}(\tau, X)=\min _{P_{e v}} C_{a g e}(d)+ \\
& V_{e v}\left(\tau-\Delta T, f_{d y n}\left(X_{e v}, P_{e v}\right)\right)
\end{aligned}
$$

As in the previous section, the result of this algorithm is composed of an optimal cost matrix $V_{e v}$ and an optimal charging power matrix $P_{e v}^{*}$ which could be applied by each vehicle regardless to other concerns. A sectional view of this policy is represented on figure 4, according to the state of energy $S o E_{e v}$ and the time before departure $\tau$, for a $E_{e v}^{\sharp}=25 k W h$ capacity.

As each vehicle can be described using the state vector $X_{e v}$, the charging policy can be used to set charging power of each vehicle among an entire fleet. It could have been possible to take into account more detailed objective functions for the optimal charging problem, for instance advanced aging models [23], grid considerations [24] or uncertain departure hour. It is here considered as upcoming concerns as the scope of this study is mainly the description of the resolution algorithm.

Here again is defined the following notation for the minimized quantity at each time step :

$\Upsilon_{e v}\left(\tau, X_{e v}, P_{e v}\right):=C_{a g e}(d)+V_{e v}\left(\tau-\Delta T, f_{d y n}\left(X_{e v}, P_{e v}\right)\right)$

\section{RESOLUTION OF THE GLOBAL PROBLEM}

As soon as some optimal policies are available for each auxiliary problem, the goal is to draw a coordination in order to reach the global optimum decision of the initial problem 


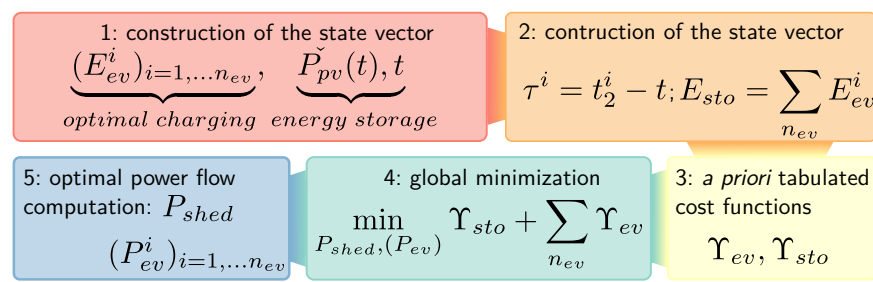

Figure 5. Resolution scheme of the power flow optimization into the collaborative system.

(6). As each auxiliary problem has already coped with time coupling and dynamic behavior of the storage, the approximation of the original problem future cost $V$ is restricted to the instantaneous collaboration trade-off. This is carried out by a minimization of the immediate costs associated to both of the previously defined auxiliary problems $\Upsilon_{e v}$ and $\Upsilon_{s t o}$. The resolution scheme is sketched on figure 5 .

The first step consists in gathering the different components of the vector state. Time $t$, available vehicle individual capacities $E_{e v}^{\sharp, i}$ and states of energy $S o E_{e v}^{i}$, measured forecast error $\Delta P_{p v}(t)$ are directly usable. Then, the equivalent storage and remaining duration for each vehicle are deduced :

$$
\begin{gathered}
E_{\text {sto }}^{\sharp}=\sum_{n_{e v}} E_{e v}^{\sharp, i} \quad S o E_{\text {sto }}=\frac{\sum_{n_{e v}} S o E_{e v}^{i} \cdot E_{e v}^{\sharp, i}}{E_{\text {sto }}^{\sharp}} \\
\tau^{i}=t_{2}^{i}-t
\end{gathered}
$$

Once state vectors $X_{\text {sto }}$ and $X_{e v}^{i}$ built, associated costs functions $\Upsilon_{e v}\left(\tau^{i}, X_{e v}^{i}, P_{e v}^{i}\right)$ and $\Upsilon_{s t o}\left(t, X_{s t o}, P_{s t o}\right)$ that have been previously tabulated can be read. The minimization of the sum of all costs is realized at each time step:

$$
\min _{U_{s t o}, U_{e v}^{i}} \sum_{n_{e v}} \Upsilon_{e v}\left(\tau^{i}, X_{e v}^{i}, U_{e v}^{i}\right)+\Upsilon_{s t o}\left(t, X_{s t o}, U_{s t o}\right)
$$

such that:

$$
P_{s t o}=\sum_{i=1}^{n_{e v}} P_{e v}^{i}
$$

As many of relevant cost functions that could be implemented are either linear or convex, an efficient minimization algorithm can be implemented. For instance, Nelder-Mead simplex has been used in this study. It permits to compute the best compromise $P_{\text {shed }}, P_{e v}^{i *}$ between global system interest and local issues of each vehicle.

At the optimum power flow $P_{e v}^{*}$, all the partial derivatives of the quantity minimized in 20 are equal to 0 . It will then satisfy for all vehicle:

$$
\frac{\partial \Upsilon_{e v}}{\partial P_{e v}^{i}}=-\frac{\partial \Upsilon_{s t o}}{\partial P_{e v}^{i}}
$$

which ensure that a vehicle would only worsen his individual decision as long as it is balanced by global improvements.

Figure 6 represents the optimal vehicle charging power following this coordination method for a 50 vehicle fleet,
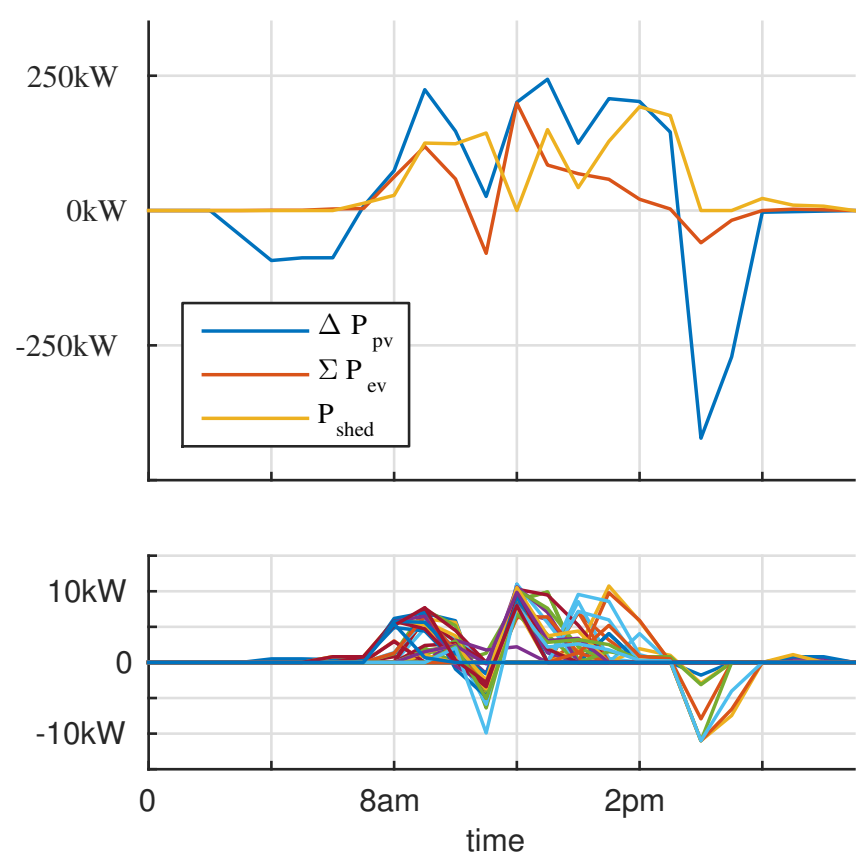

Figure 6. Upper graph: example of the charging power for a $50 \mathrm{EV}$ fleet, coordinating optimal policies $P_{\text {sto }}^{*}$ and $P_{e v}^{*}$, same parameters as figure 3 . Lower graph: charging power of each vehicle.

under the same situation as figure 3. The behavior of the fleet is randomly generated using French mobility statistics [25]. Each vehicle capacity is also random, according to the EV market shares in 2013. The equivalent capacity of this fleet is $1.25 M W h$. As expected, the mitigation of the forecast error can be achieved as long as vehicles are available. Over estimations of the production on the morning and the evening of the example day could be compensated when using a stationary storage. It is no longer possible with a fleet which is not supposed to be operable from home.

\section{CONCLUSION AND UPCOMING DEVELOPMENT}

In this paper, a framework called collaborative system has been presented to concurrently give a mathematical shape to several situations, such as solar charging station for electric vehicles or PV plant selling its production on the energy market. In the broader scope, it aims at ensuring sustainable mobility while making easier the integration of renewable into the grid by introducing a day ahead power commitment not on the single PV production nor vehicle consumption, but on the difference of this two quantities. Shedding some of the maximum producible power by shifting the operating point and modulating the charging power of vehicles can be used to meet the commitment profile.

The operational management of this system is build as a large dimension and multi time step optimization problem, in a stochastic framework because of the random PV forecast error and vehicle availability. Several competing objectives have here been taken into account: user mobility, battery aging, grid penalties for commitment deviation and shedding power. This is not an exhaustive list as the scope is here to dress several 
operational problems in a formal context and to propose a resolution method which can both handle stochasticity, high dimension and time coupling.

The proposed resolution firstly solves the case of a PV plant with a stationary storage. So as to cope with the random nature of the PV production forecast error, a specific and original modeling is used - although it could not been further described in this paper - using a hierarchical classification of forecast error trajectories. A resolution by stochastic dynamic programming is thereafter carried out so as to compute a strategy which indicates the optimal stored power and shedding power for each possible value of the state vector. Secondly, a strategy is built to describe the charging of any vehicle, described by its battery capacity, state of energy and time before leaving. Those strategies are off-line computed to make easier the operational decision making. Then at each time step and according to the measured situation, a minimization of the total cost - the sum of each vehicle cost and the equivalent stationary storage cost - is realised. This enables to perform the optimal power flow in a 50 vehicle fleet and a 1 hour time step in $0.5 \mathrm{~s}$ a day. However, further investigations should be carried out to assess the quality of this approximation of the future cost.

As we mainly focused here on a resolution method for an optimization problem which covers several very different situation, it was not possible to put the emphasis on the definition of precise objective function for user mobility, battery aging, et caetera. Moreover, a real agent such as for instance a PV plant on an energy market, would define a precise business model, ie a specific way to combine those different objective functions. Because of the lack of economic or business model, we have elected an environmental point of view to describe objective functions as primary energy costs. The goal was therefore to minimize the sum of all costs as an overall general welfare. Further work will then provide some examples of this resolution scheme in more precise situations and also from an economy perspective.

\section{REFERENCES}

[1] Canova, A., Giaccone, L., Spertino, F., Tartaglia, M. (2009). Electrical impact of photovoltaic plant in distributed network. Industry Applications, IEEE Transactions on, 45(1), 341-347.

[2] Manjunatha, A. P., Korba, P., Stauch, V. (2013, June). Integration of large battery storage system into distribution grid with renewable generation. In PowerTech (POWERTECH), 2013 IEEE Grenoble (pp. 1-6). IEEE.

[3] Doukas, D. I., Bakas, P., Marinopoulos, A., Kim, H. (2013, June). Energy storage integration into grid connected utility-scale photovoltaic (PV) systems. In PowerTech (POWERTECH), 2013 IEEE Grenoble (pp. 1-6). IEEE.

[4] M Lippert, C Jeuffrain, S Lascaud, P Rioual, Making the Sun Reliable with Li-Ion Energy Storage : Solar PV Energy management for large PV power plants on isolated islands, 5th World Conference on Photovoltaic Energy Conversion, 6-10 September 2010, Valencia, Spain, pp 38123820

[5] Kempton, W., Tomi, J. (2005). Vehicle-to-grid power implementation: From stabilizing the grid to supporting large-scale renewable energy. Journal of Power Sources, 144(1), 280-294.

[6] Guillou, H., Cung, V. D., Ha, D. L., Jacomino, M., Merten, J. (2011, September). Energy management strategies for optimal charging of electric vehicles with photovoltaic production. In Proceedings of the 26th European photovoltaic solar energy conference and exhibition (pp. 3885-3889).

[7] Gonzalez Vaya, M., Andersson, G. (2013, June). Integrating renewable energy forecast uncertainty in smart-charging approaches for plug-in electric vehicles. In PowerTech (POWERTECH), 2013 IEEE Grenoble (pp. 1-6). IEEE.

[8] Le Goff Latimier, R., Kovaltchouk, T., Ben Ahmed, H., Multon, B. (2014, March). Preliminary sizing of a collaborative system: Photovoltaic power plant and electric vehicle fleet. In Ecological Vehicles and Renewable Energies (EVER), 2014 Ninth International Conference on (pp. 1-9). IEEE.

[9] Robu, V., Kota, R., Chalkiadakis, G., Rogers, A., Jennings, N. R. (2012, June). Cooperative virtual power plant formation using scoring rules. In Proceedings of the 11th International Conference on Autonomous Agents and Multiagent Systems-Volume 3 (pp. 1165-1166). International Foundation for Autonomous Agents and Multiagent Systems.

[10] Binding, C., Gantenbein, D., Jansen, B., Sundstrom, O., Andersen, P. B., Marra, F., ... and Trholt, C. (2010, July). Electric vehicle fleet integration in the danish EDISON project-A virtual power plant on the island of Bornholm. In Power and Energy Society General Meeting, 2010 IEEE (pp. 1-8). IEEE.

[11] Thiaux Y., Seigneurbieux J., Multon B., Ben Ahmed H. (2010, March). Load Profile Impact on the Gross Energy Requirement of Stand-Alone Photovoltaic System. In Renewable Energy Journal Elsevier, n35 (2010) pp.602613.

[12] Clastres, C., Pham, T. H., Wurtz, F., Bacha, S. (2010). Ancillary services and optimal household energy management with photovoltaic production. Energy, 35(1), 55-64.

[13] Codani, P., Petit, M., Perez, Y. (2014). Missing money for EVs: economics impacts of TSO market designs. Available at SSRN 2525290.

[14] V. Fthenakis, H. C. Kim, R. Frischknecht, M. Raugei, P. Sinha, M. Stucki , 2011, Life Cycle Inventories and Life Cycle Assessment of Photovoltaic Systems, International Energy Agency(IEA) PVPS Task 12, Report T12-02:2011.

[15] McManus, M. C. (2012) Environmental consequences of the use of batteries in low carbon systems: The impact of battery production. Applied Energy, 93. pp. 228-295.

[16] D. P. Bertsekas, Dynamic Programming and Optimal Control. Athena Scientific, 3rd edition, 2005.

[17] Leterme, W., Ruelens, F., Claessens, B., Belmans, R. (2014). A Flexible Stochastic Optimization Method for Wind Power Balancing With PHEVs. Smart Grid, IEEE Transactions on, 5(3), 1238-1245.

[18] P. Haessig, T. Kovaltchouk, B. Multon, H. Ben Ahmed, and S. Lascaud, Computing an Optimal Control Policy for an Energy Storage, in 6th European Conference on Python in Science (EuroSciPy 2013), Brussels, Belgium, Aug. 2013, pp. 51-58

[19] Pinson, P., Madsen, H., Nielsen, H. A., Papaefthymiou, G., Klckl, B. (2009). From probabilistic forecasts to statistical scenarios of shortterm wind power production. Wind energy, 12(1), 51-62.

[20] Seity, Y., Brousseau, P., Malardel, S., Hello, G., Bnard, P., Bouttier, F., ... Masson, V. (2011). The AROME-France convective-scale operational model. Monthly Weather Review, 139(3), 976-991.

[21] Pereira, M. V. F., Pinto, L. M. (1991). Multi-stage stochastic optimization applied to energy planning. Mathematical Programming, 52(1-3), 359-375.

[22] Barty, K., Carpentier, P., Girardeau, P. (2010). Decomposition of largescale stochastic optimal control problems. RAIRO-Operations Research, 44(03), 167-183.

[23] Haessig, P., Multon, B., Ben Ahmed, H., Lascaud, S., Jamy, L. (2013, June). Aging-aware NaS battery model in a stochastic windstorage simulation framework. In PowerTech (POWERTECH), 2013 IEEE Grenoble (pp. 1-6). IEEE.

[24] Stotzer, M et al., Concept and potential of electric vehicle fleet management for ancillary service provision. IEEE PowerTech, 2013.

[25] Maurel, F., Depoorter, S., Assimon, P.-M., Perspective on Electric Vehicles (in french), Commissioner-General for Sustainable Development, 2011 